Int. J. Electrochem. Sci., 11 (2016) $9676-9686$

\title{
Effect of Zincating bath additives on structural and electrochemical properties of electroless Ni-P coating on AA6061
}

\author{
Amir Farzaneh $^{1}$, Mostafa Sarvari ${ }^{2}$, Maryam Ehteshamzadeh ${ }^{2, *}$, Omer Mermer $^{3, *}$ \\ ${ }^{1}$ Department of Materials Science and Engineering, Faculty of Mechanical Engineering, University of \\ Tabriz, Iran \\ ${ }^{2}$ Department of Materials Science and Engineering, Faculty of Engineering, Shahid Bahonar \\ University of Kerman, Iran \\ ${ }^{3}$ Department of Electrical and Electronics Engineering, Ege University, İzmir, Turkey \\ *E-mail: ehtesham@mail.uk.ac.ir, omer.mermer@ege.edu.tr
}

doi: $10.20964 / 2016.11 .75$

Received: 12 August 2016/ Accepted: 20 September 2016 / Published: 10 October 2016

Electrochemical behavior of electroless nickel phosphorus (EN-P) coated aluminum 6061 alloy combination in different zincating conditions have been evaluated. The effect of the zincate additives (anionic surfactant sodium dodecyl sulfate (SDS) and copper sulfate) on structure and morphology of zincating and electroless EN-P deposition have been studied. Corrosion performance of the prepared samples was studied by polarization and electrochemical impedance spectroscopy (EIS). Scanning electron microscope (SEM), Energy dispersive X-ray spectroscopy (EDS) and X-ray diffraction (XRD) analysis were used for studying surface morphology and chemical composition of coatings. According to the obtained results, the zincate solution containing copper sulfate and SDS surfactant indicated the fast deposition of $\mathrm{Zn}$ and dense nucleation with small $\mathrm{Zn}$ particles at the surface. This $\mathrm{Zn}$ films resulted in dense and small grains of EN-P deposition with smooth surfaces.

Keywords: Al 6061 alloy; Zincate treatment; surfactant; electroless nickel phosphorus; Electrochemical behavior

\section{$\underline{\text { FULL TEXT }}$}

(C) 2016 The Authors. Published by ESG (www.electrochemsci.org). This article is an open access article distributed under the terms and conditions of the Creative Commons Attribution license (http://creativecommons.org/licenses/by/4.0/). 